\title{
Construction Research and Practice of Landscaping Course
}

\author{
Wenjun Wang ${ }^{1}$ and Hongxing $\mathrm{Yi}^{2}$ \\ ${ }^{1}$ Arts Department City College of WUST, Wuhan, Hubei 430083; \\ ${ }^{2}$ Arts Department City College of WUST, Wuhan, Hubei 430083
}

Keywords: Garden landscape design; Landscape design; Teaching reform; Teaching practice

\begin{abstract}
At present, the environmental art design course in art and architectural institutions or "landscaping" in landscape architecture and other related courses value theory more than practice; combined this phenomenon with the prominent problem existing in teaching process, according to the learning characteristics of students, the teaching contents, methods and ways should make targeted modifications; in addition, the content and set of curriculum should also be reformed. Optimization should make from the basic theory, case study, curriculum design and other aspects. At the same time, strengthen the practice of content, start from the survey, mapping, analysis and other aspects, making students have better understanding of early theoretical knowledge, then they can link the theory with practice well so as to learn and apply elastically. Through the optimization of the curriculum, students are more familiar with various attributes of pants in landscaping so that they can make planting design more reasonable and skilled.
\end{abstract}

\section{Introduction}

Landscape design is a Comprehensive strong professional, and landscaping is also one of the required course that landscape design professional course. To know and master the plant ecological habits, is one of the important tasks and with those knowledge landscaping will achieve expected effect. The landscape design of the desired effect. In the teaching plan landscaping course have 64 classes, how to reasonable arrange the theoretical and practice course, recognize the plants, be familiar with the characteristics of the plant and planting design principle and so on, to make these problems to be solved is a problem we have to fix.

At present, in the course of teaching of undergraduate course teaching content, teaching method and practice content still exist some limitations, leading to the course content should not be understood system, complete. In the end students can not afford the real work. This course content mostly focus on the process of teaching theory but ignore the technology. This phenomenon is widespread. Traditional teaching methods is given priority to do drawing training, field visiting, there is no clear intention and examination evaluation system, and the lack of specific demonstration, causing students obsessed with landscape plan design and ignore the last stage of in-depth study. Drawing only know how to make the them look nice but do not care about it can be carry out or not. Such teaching methods go against the students' employment and career development for a long time.

\section{Current Situation and Problems}

Existing Situation. As one of the important elements in landscape design, plant them in the landscape is not a dispensable thing in the world, regardless of landscape scale, cannot leave the plant. Push forward the process of urbanization and the continuous development of science and technology, roof garden, vertical greening is more and more popular. But students grasp of plants is limited, as a result of this, landscape design looks very beautiful, but the drawings in plants, the student is not based on the ecological characteristics of the plant for their reasonable design.

Existing Problems. Plants the biggest characteristic is that it is a life, a lot of plants is rich in the seasonal change, make people able to perceive the seasons change. Even evergreen plants, with the passage of time, also continues to grow, the subtle changes. Plant these characteristics will surely increase the difficulties of the students' learning and understanding plant. In the teaching process of 
the concrete is the biggest problems facing the design good landscape design, the figure of arbor, shrub and herb, how to configure the effect after the configuration without basic concepts. In students' understanding of the garden plant stems from the classroom teacher's image data and boring difficult-to-remember plant ecological habits, the monotonous traditional rote learning method is difficult to let the students have a strong interest in learning. Therefore, it is necessary to practice teaching part of garden plant course targeted optimization.

\section{The Optimization of Teaching Contents}

After a long period of teaching practice and observation, a simple multimedia cramming teaching effect it is often difficult to get good feedback, the wasted effort. Increased from adjusting teaching links, each link of the coherence and interest, interaction between teachers and students, enrich the practice teaching and course design of a series of aspects, to improve students' learning motivation. 0

For landscape design professional, need knowledge and understanding of plant, but it is different from knowledge of plants need to cover every agricultural colleges, landscape design professional course focuses on two aspects: understand plant ecological habits and plants design principle and method. Courses should be appropriately increased, therefore, the practice and the rich teaching more interesting and diversity, and the concrete can be from the following several aspects (Table 1):

Table 1 Landscaping course content

\begin{tabular}{|c|c|c|}
\hline chapter & period & main content \\
\hline overview & 2 & $\begin{array}{l}\text { Chapter and verse, case introduction, improve the } \\
\text { students' learning interest }\end{array}$ \\
\hline classification and features & 6 & The function of garden plant and design key points \\
\hline ecological characteristic & 4 & Basic habits and characteristics of garden plants \\
\hline investigate & 24 & $\begin{array}{l}\text { Different types of landscape, surveying and mapping, } \\
\text { mapping, investigation reports, etc }\end{array}$ \\
\hline case analysis & 8 & $\begin{array}{l}\text { Introduction to classical landscape case, analyzing the } \\
\text { characteristics of the planting design }\end{array}$ \\
\hline curriculum design & 20 & $\begin{array}{l}\text { Site analysis, program design, program modification } \\
\text { and construction drawings, project presentation, } \\
\text { students mutual, teachers' comments }\end{array}$ \\
\hline
\end{tabular}

Curricula Construction. Good teaching materials and courseware can certainly improve the teaching effect, but at present a lot of teaching material quality the good and bad are intermingled, so need to screen, choose landscape professional teaching materials, and non-agricultural use in colleges and universities of trees, flowers and other professional books. To the plant landscape of professional learning and understanding of plants in agricultural colleges have distinction, cannot treat as the same, need to be targeted to choose textbooks or organize teaching experienced teachers teaching materials or notes. The making of multimedia courseware give full consideration to students' learning features combining with teaching material or notes, corresponding, lets the student in the class can also be quickly when reviewing of teaching content. At the same time, the content of the multimedia courseware to keep pace with The Times, the latest and most classic case and combine the contents of boring, improve the enthusiasm of students bloodshot.

Information while one-way transmission of the multimedia courseware can help students well understand the main content of teachers' teaching, but the field survey, investigation and stage students will meet all kinds of problems. Therefore, it is necessary to organize related professionals, develop the APP, help students to obtain knowledge more efficiently, help students knowledge accumulation of plant, in our daily life deepen our memory.

To Improve the Traditional Teaching Mode. Landscape greening course is a comprehensive and practical very strong curriculum, the traditional teaching mode is more in the classroom by the 
teacher teaching, using multimedia to watch courseware manner, the result is content boring, students interested in little awkward situation, the teaching effect nature cannot be guaranteed.

Rich teaching, to improve traditional model of teaching is given priority to with the classroom and teaching materials. Reasonable decorate high interest and participation of teaching links, increase students' learning fun, fun. Such as, case analysis, not the teacher to explain in detail the advantages and disadvantages of the case from beginning to end, but the group discussions, statements to power; Collect course teaching of plant leaves, making specimen; Production plant ecological habits form link, etc. Contact more closely link course arrangement, fully arouse the enthusiasm of students, but also reduce the pressure for teachers improve the students' self-study ability, fully staffed.

The Field Practice Teaching Link of Multiple Scenarios. Plants as one of the important material of landscape design, students in the classroom to see the plant picture is not intuitive, and reality of plants are more or less a certain gap. Pictures are not able to complete the reaction of the plants of characteristics, such as leaf size; flowers; leaves or flowers plant characteristics such as aroma. Therefore classroom in landscape greening should be from indoor to outdoor; From the familiar environment to the unfamiliar environment; From small landscaping to expand into large-scale afforestation. Rich practical teaching links, such as: students the most familiar is the campus. From the side the most familiar, the most common plants, not only can improve the students' interest in learning, and to observe the seasonal changes of plant in different seasons.

Secondly, by divide students into several groups, for different types and scale of landscape live-action fieldwork, rendering the scene of the flat, elevation, section, production of nursery stock table, etc., combining with the scene photos, making PPT, complete inspection report, summary analysis of the pros and cons of the venue, the pros and cons of planting design. Through such a site investigation activities, that is, to consolidate the books boring theory knowledge, can also stimulate students learning enthusiasm and creativity.

Finally, practice is the sole criterion for testing truth, by the same token, the test students' strengths and weaknesses of the landscape design not only to the design drawing is good or bad. But let the student completed personally from drawings to real practice, the landscape design so that they will have a more in-depth understanding, will be better to combine theory with practice. Therefore, can make full use of school resources, open up the landscape design practice, let the students a deeper understanding of landscape design. Such as school buildings top surface is a good choice. The first roof garden is an important part of city to create sponge, at the same time can also beautify the campus environment, save energy. The students can be in the top of the building set up their own "happy farm", combined with previous theory knowledge, reasonable to design drawings, finally to check the feasibility of work through practice. Compared with traditional course assignments, stop drawing design, practice can make students better understand the drawings and the reality gap, and then summarizes the design experience of has practical value.

\section{Curriculum Design}

The investigation from the early stage of the theory of knowledge accumulation, to learn and know plants, to the curriculum design, on the drawings, and complete the landscape design of a real, though not very big, but rich in details. Summarizes the ideal and the reality gap so late is no longer a repeat. In the late course to complete the course design is the summary of the course to early.

Teachers plan and space environment photos of real and practical investigation. Let students to get rid of the false questions do really awkward situation. Although fake problem can really do, but after the completion of the design of effect cannot be tested. The prior knowledge of theory and case analysis as the design theory of student support, on-site research learning and understanding of plant is the curriculum design of technical support. In students of site analysis, program design, program modification and construction drawings, project presentation, students mutual, teachers review, there is no doubt that can improve the students' interest in learning and teaching effect. The purpose of the course is not only design and drawing, communication skills also cannot ignore, to cultivate interdisciplinary talents of high quality should be comprehensive, oral expression ability 
training should also be time passes through in the middle of the course. Finally, completed a detailed course summary, to summarize the whole course, convenient the student later targeted to improve.

\section{Conclusion}

Results from the course feedback opinion, after the adjustment course in the content of practicability, student's beginning ability and oral expression ability, understanding of drawing ability, the role of plants in landscape design has a deeper understanding. Combined with the continuous development of science and technology, current teaching of the course and the course content needs to be constantly updated, in the form of a rich, full, interesting teaching with greater participation practice, let the students can better grasp of the course difficult point, exercise the students' ability of drawing, the beginning ability, oral expression ability, cultivating high quality landscape design talents.

\section{Acknowledgement}

The research topic of City College of WUST 2016, landscape design- landscaping curriculum construction research and practice. Item number: 2016CYYBJY024.

\section{References}

[1] H.H Hu, S.F Gong and J.G Wang, Reform Research and Practice in Garden Plant Landscape Course [J].Journal of Northeast Agricultural University,2008,6(3):85-87.

[2] X.H Sun, Planning and Design of Plant Landscape [M]. The first edition. Beijing: China Forestry Publishing House, 2012.

[3] W.S Chi, Color Design of Plant Landscape [M]. Dong Li Translation. The first edition. Beijing: China Forestry Publishing House, 2007.

[4] J Zhang, S.Y Liu, On the Teaching of Garden Plant Landscape Design [J]. Anhui Agricultural Science Bulletin, 2010, 16(16):150-151.

[5] Y.H Liu, Design of Plant Landscape borders [M].The First Edition. Shanghai: Shanghai Science and Technology Press, 2010.

[6] P.Y Hao, G.H Li and H Yin, etc. Study on Optimization of Course Organization in "Garden Plant Landscape Planning" of Beijing Forestry University [J]. Forestry Education in China, 2015, 33(1):68-70.

[7] Y.M Shen, etc. Thought on Teaching Reform of Garden Plant Landscape Design [J].Journal of Beijing Forestry University, 2007(S):120-122.

[8] Y Tian, Discussion on Teaching Reform of Planting Design for Garden Major[J].Anhui Agricultural Science Bulletin,2009,15(11):212-213.

[9] D.J Shao, Research on Design Method in Chinese Traditional Garden Planting [D].Beijing: Beijing Forestry University, 2012, 16(16):110-114.

[10]L Dong, Related Courses Evolution and Thought of Garden Plant Landscape Planning [J].Chinese Landscape Architecture, 2011(27):103-106.

[11]M.X Wang, L Dong and H Yin, On Practice Teaching Reform of "Garden Plant Landscape Planning" [J].Forestry Education in China,2011,29(2):71-73. 